\title{
Vibration Absorption using KDamper-based Devices with Extreme Geometric Nonlinearity
}

\author{
Konstantinos A. Kapasakalis ${ }^{1 *}$, Evangelos J. Sapountzakis ${ }^{1}$, \\ Institute of Structural Analysis and Antiseismic Research, School of Civil Engineering, \\ Zografou Campus, National Technical University of Athens, GR-157 80 \\ Greece
}

Received: March 13, 2021. Revised: January 7, 2022. Accepted: January 22, 2022. Published: February 10, 2022.

\begin{abstract}
A KDamper oscillator is proven to be a more effective alternative to conventional Tuned Mass Damper (TMD) approaches and Quazi Zero Stiffness (QZS) or negative stiffness isolators. In this paper, an extended version of the KDamper (EKD) concept is employed to control the dynamic responses of an undamped (or low damper) SDoF system subjected to various dynamic loads. The KDamper consists of an additional mass, artificial dampers, and positive and negative stiffness elements. The additional implemented mass is one order of magnitude smaller as compared to most mass related vibration absorbers (TMDs, TMDIs, KDampers, etc.). The artificial dampers and the stiffness element values are selected following an engineering-criteria driven optimization procedure that accounts for geometric constraints and manufacturing limitations. The negative stiffness element is realized with an articulated mechanism that employs pre-stresses conventional stiffness elements (spiral springs) and generates controlled negative stiffness (NS). In order to exploit the advantages that the inherent nonlinear nature the NS offers, such as robustness, broadband response and energy sinks, the proposed dynamic vibration absorber is designed to present significant geometric nonlinearity, that varies from none (linear system) to extreme. Thus, different test cases are presented with respect to the desired nonlinearity of the generated NS, as well as to the type of the external load subjected to the structure. This way we can determine in which cases extreme geometric nonlinearity is beneficial to the dynamic behavior of the controlled structure.
\end{abstract}

Keywords-Vibration absorption, Extreme geometric nonlinearity, Negative stiffness isolators, Tuned Mass Dampers

\section{INTRODUCTION}

$\mathrm{T}$ HE KDamper concept is essentially a combination of a classic Tuned Mass Damper with a negative stiffness element.

In the literature there are numerous passive, semi-active and active vibration control techniques, which among them, the Tuned Mass Damper, TMD (implementation of an additional mass) is perhaps the most popular and mature theory. The TMD, which is a commonly known dynamic vibration absorber, is a classic mechanical device that consists of an additional mass, a positive stiffness element (spring), and a viscous damper. In most cases, it is attached to a vibrating primary system/structure, to suppress any unwanted vibrations induced by wind and earthquake loads. The first theoretical application of the TMD concept was made by Frahm [1]. Later Den Hartog [2] made the first proposition of optimal design theory for the TMD for an undamped SDoF structure, and since then, the TMD has been implemented on a vast array of structures with the most interesting case being skyscrapers [3][6]. A characteristic example of its implementation on skyscrapers can be found in one of the tallest buildings in the world, Taipei 101 Tower (101 stories, $504 \mathrm{~m}$ ) in Taiwan [7]. Recent studies also include the use of TMDs for vibration absorption in seismic or other forms of excitation of structures [8], wind and wave excitation in wind turbines by [9] and torsional vibrations in rotating and reciprocating machines by [10]. Semi-active, active and non-linear configurations are also developed and found in [11]-[15]. The Active TMD (ATMD) is a hybrid devise that consists of a classic/passive TMD supplemented by an actuator parallel to the spring and damper. It is a widely known configuration in vibration control of structures and has been proved to yield enhanced damping performance [16], [17]. The disadvantage of such absorbers is that their effectiveness is directly affected by the accuracy of the actuators' output, which over time can have an alternation in its performance by false estimating the desirable function of the vibration mitigation approach and eventually burden the 
structure.

The use of negative stiffness elements (or "anti-springs") for vibration absorption was initially introduced in the pioneering publication of Molyneaux [18], as well as in the milestone developments of Platus [19]. The central concept of these approaches is the significant reduction of the equivalent system's stiffness, which as a result, decreases the nominal system frequency (the system's natural period is increased) even at almost zero levels, as in [20], thus, called "Quasi-Zero Stiffness" (QZS) oscillators. In this way, enhanced vibration mitigation is achieved, since the system exhibits reduced transmissibility for all operating frequencies above the natural one.

The negative stiffness behavior is primarily achieved by special mechanical designs involving conventional positive stiffness pre-stressed elastic mechanical elements, such as post-buckled beams, plates, shells and pre-compressed springs, arranged in appropriate geometrical configurations. Some interesting designs are described in [21] and [22]. However, alternatively to elastic forces, other forms of physical forces can be used to produce an equivalent negative stiffness effect, such as gravitational [23], magnetic [24] or electromagnetic [25]. However, when dealing with seismic effects mitigation on buildings or bridge structures, where the values of negative stiffness required are quite high, elastic forces seem to be the only feasible choice.

Among others, Quazi Zero Stiffness (QZS) oscillators are finding numerous applications in seismic protection [26]-[29], in all types of automotive suspensions [30]-[32] or in torsional vibrations [33]. Quite recently, periodic cellular structures with advanced dynamic behavior have been also proposed [34]-[37], combining high positive and negative stiffness. Although the physical mechanisms that generate increased damping in cellular structures are not well understood, microbuckling or slip-stick phenomena [38]-[40], could be among the possible explanations.

In the meantime, quite interesting possibilities towards achieving significant damping have been demonstrated to exist also in materials comprising a negative stiffness phase [41], not only at a material level [42], but also at macroscopic devices [43]. In addition, such a behavior can be combined with high stiffness properties. A theoretical approach has been performed for the analysis of the static and dynamic stability of composite materials that incorporate negative stiffness elements [44]. However, the main disadvantage of Quazi Zero Stiffness (QZS) oscillators is the requirement for the overall stiffness of the system to be reduced significantly, even close to zero levels, fact that limits the static load bearing capacity of structures controlled with such absorbers.

A promising class of absorbers is based on increasing the damping by the appropriate introduction of negative stiffness elements. Recently, Antoniadis [45] proposed a stiff and stable linear oscillator that incorporates a negative stiffness element. This novel type of oscillator can exhibit extraordinary damping properties. Moreover, the damping ratio of flexural waves propagating within layered periodic structures that incorporate such NS oscillators is increased by several orders of magnitude [46]. A similar concept, that introduces a negative stiffness amplifying damper, is proposed in [47] and [48], and is proven to achieve significant damping magnification effects.

Exploiting the advantages of the traditional Tuned Mass Dampers and the 'Quazi Zero Stiffness' design, a novel passive vibration absorption and damping concept, the KDamper concept, has been proposed in [49]. The KDamper incorporates a negative stiffness element, that exhibits extraordinary damping properties, without presenting the drawbacks of the traditional linear oscillator, or of the negative stiffness (QZS) concepts. This vibration absorber is designed to maintain the total (static) stiffness as a traditional reference original oscillator. However, it differs both from the original SDoF oscillator, as well as from the known negative stiffness oscillators (QZS), by appropriately redistributing the individual stiffness elements and by reallocating the damping. Although the proposed vibration absorber employs a negative stiffness element, its parameters are properly selected in order for the system to remain stable in static as well as in dynamic conditions. The presence of an additional mass also serves in mitigating the effects of a vibrating load, operating as an energy dissipation mechanism (energy is transferred from the structure to the additional mass). The device overcomes the sensitivity problems of TMDs as the tuning is mainly controlled by the negative stiffness element's parameters.

The KDamper, and the extended versions of it, have been effectively implemented for horizontal [50]-[54] and vertical [55]-[57] seismic protection of structures, as well as for vibration absorption of wind turbine towers [58]-[61]. The complexity of the KDamper-based designs did not allow for the inherent nonlinear nature of the negative stiffness behavior to be accounted for. As a result, simple mechanical configurations were developed for the realization of the NS element, that generated linear (0-5\% geometric) NS.

In this paper, a realistic configuration is presented that employs common positive stiffness elements in an articulated mechanism, that can generate controlled NS. The proposed configuration enables the implementation of multiple linear springs. As a result, manufacturing limitations that occur from buckling phenomena and exceedance of torsional strength can be avoided. In this way, extreme geometric nonlinearity can be accounted in the design as a free design variable. More specifically, a closed form for the generated NS is obtained, which is pre-determined by properly selecting the system parameters and the maximum variation of the generated NS.

An engineering-criteria driven optimization procedure is followed in order to properly design the EKD, that accounts for geometric constraints as well as manufacturing limitations. This way, the advantages of extreme geometric nonlinearity can be examined with respect to the structural problem and the loading type. More specifically, two different test cases are presented: (a) in the first one the imposed dynamic load has an 
impulsive nature representing wind gusts, and in the second one (b) a seismic load is considered.

More specifically, in Section 2 of the paper, a brief overview of the extended version of KDamper (EKD) is introduced. All the components of the EKD are presented along with the equations of motion of the system. A conceptual design for the realization of the negative stiffness element (NS) is proposed, that generates controlled geometric nonlinear NS. A design variable is presented, regarding the maximum variation of the NS, that is later accounted in the optimization procedure. In Section 3, a constrained optimization procedure for the design of the EKD is presented, that accounts for geometric constraints and manufacturing limitations (variations in stiffness values, realistic range for all the EKD components, limits in the system dynamic responses, etc.). Finally, in Section 4 two numerical examples are investigated, in order to verify the effectiveness of the EKD.

\section{Methodology}

The extended version of the KDamper oscillator [51] (EKD) is presented in Figure 1 and consists of a combination of positive and negative stiffness elements, artificial dampers, and an additional mass. A negative stiffness element $\left(k_{N S}\right)$ along with an artificial damper $\left(c_{N S}\right)$, placed in parallel to $k_{N S}$, connect the structure mass $m$ with the added mass $m_{D}$. Furthermore, a positive stiffness element $\left(k_{P S}\right)$ and an artificial damper $c_{P S}$ (parallel to $k_{P S}$ ) connect the additional mass $m_{D}$ to the base/foundation. Finally, the structure's mass is connected directly to the base of the structure/foundation with a positive stiffness element $k_{R}$.

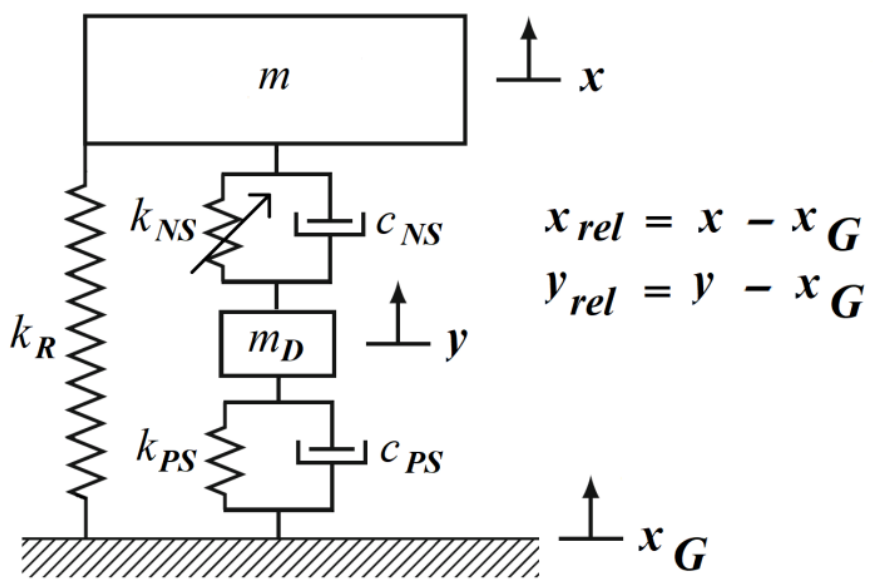

Figure 1. Analytical mechanical model of SDoF system controlled with an extended version of the KDamper vibration absorber

The EKD can be used as a supplement to an originally undamped (or low damped) SDoF system in order to mitigate its dynamic responses. It has been proven that it can effectively reduce the structural accelerations, retaining at the same time the required displacements in reasonable ranges, as compared to other vibration absorption approaches (base isolation, TMDs, QZS) [51]. Alternatively, it can be used to mount a new structure of mass $m$, and isolate the induced vibrations (mechanical/machinery equipment). The equations of motion of this configuration subjected to a ground motion $x_{G}(t)$, and/or an external force $P(t)$ are:

$$
\begin{aligned}
& m x_{r e l}+c_{N S}\left(x_{r e l}-y_{r e l}\right)+k_{R} x_{r e l}+k_{N S}\left(x_{r e l}-y_{r e l}\right) \\
& =-m x_{G}(t)+P(t) \\
& m_{D} y_{r e l}-c_{N S}\left(x_{r e l}-y_{r e l}\right)+c_{P S} y_{r e l}-k_{N S}\left(x_{r e l}-y_{r e l}\right) \\
& +k_{P S} y_{r e l}=-m_{D} x_{G}(t)
\end{aligned}
$$

where $x_{r e l}$ and $y_{r e l}$ are the relative to the ground displacements of the structure and the additional mass, respectively, as presented in Figure 1.

The artificial dampers $\left(c_{N S}, c_{P S}\right)$ can be realized with common linear dampers, while the positive stiffness elements $\left(k_{P S}, k_{R}\right)$ can be realized with conventional linear springs (e.g., spiral springs).

The negative stiffness behavior can be achieved with various configurations, with respect to the application to be examined. In the case where the NS element is implemented as a device for vibration absorption of structures (e.g., seismic protection), the necessary elastic forces required can only be generated with special mechanical designs involving conventional positive stiffness pre-stressed elastic mechanical elements, such as post-buckled beams, plates, shells and precompressed springs, arranged in appropriate geometrical configurations. Depending on the parameters of the NS mechanism, the system can generate negative stiffness that varies from linear up to extreme nonlinear (geometric).

In previous work of KDamper-based concept, the adopted configuration was designed either assuming that the NS was constant (linear NS), or by properly selecting the parameters of the negative stiffness mechanism in order for the generated NS to present small variations in the range of $5-10 \%$.

In this work, the NS is realized with an articulated mechanism that employs pre-compressed spiral springs [20], [49], as presented in Figures 2-4. A number of horizontal conventional positive stiffness elements $\left(k_{H}\right)$ are connected with the structure's mass by being attached in the rigid block presented in Figure 2.

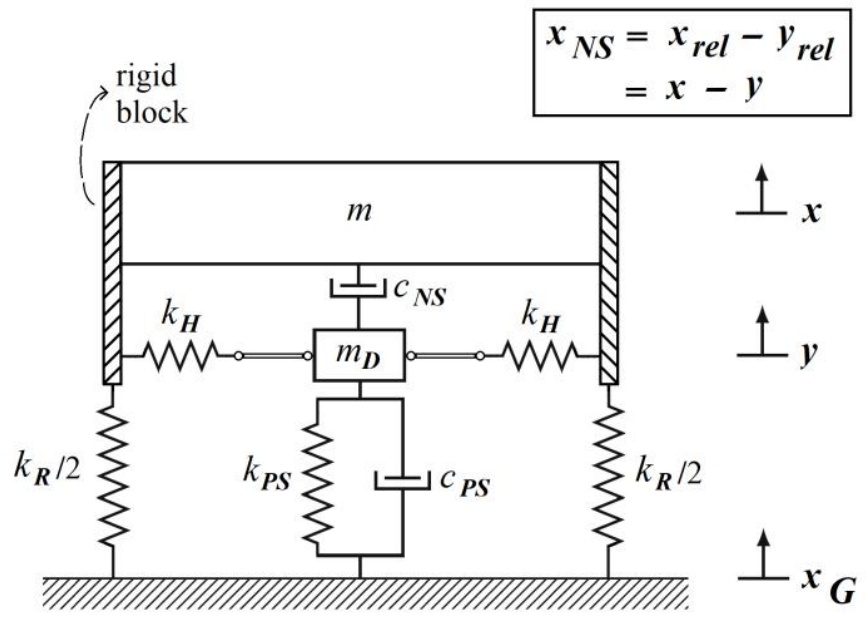

Figure 2. Schematic representation for the physical realization of the 
NS element with pre-compressed spiral springs that generate controlled negative stiffness (front view)

In Figure 3, the proposed mechanism is presented in its initial equilibrium position, as well as in its deformed state, in order to better present the negative stiffness behavior. Since the positive stiffness elements $k_{H}$ are pre-stressed, the generated vertical force that is transferred to the added mass by the articulated mechanism is in the same direction as the negative stiffness stroke $x_{N S}$, thus generating NS.

In Figure 4, a plan view of the proposed NS mechanism is presented. The conventional positive pre-stressed spiral springs are positioned radially with respect to the additional mass's vertical axis. As a consequence, when the additional mass moves in the vertical direction, all the pre-stressed elements induce a force $\left(f_{N S}\right)$ in the additional mass that assists the motion of $m_{D}$ instead of opposing it, thus generating negative stiffness. This proposed configuration enables the implementation of multiple springs with constant $k_{H}$, thus avoiding safety issues in the pre-stressed springs as, buckling, exceedance of torsional strength, etc.
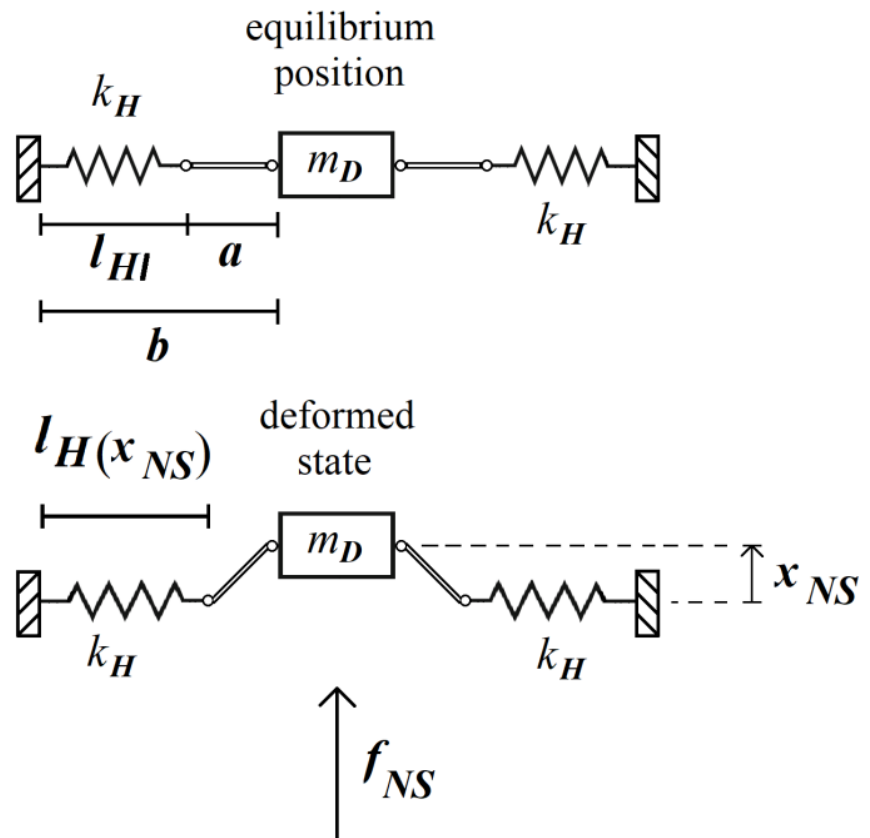

Figure 3. Proposed negative stiffness configuration in its initial equilibrium position, and in its deformed state, that generates vertical negative stiffness by employing horizontal conventional stiffness elements (front view)

The equations of motion of the controlled system with EKD thus become:

$$
\begin{aligned}
& m x_{r e l}+c_{N S}\left(x_{r e l}-y_{r e l}\right)+k_{R} x_{r e l}+f_{N S\left(x_{N S}\right)} \\
& =-m x_{G}(t)+P(t) \\
& m_{D} y_{r e l}-c_{N S}\left(x_{r e l}-y_{r e l}\right)+c_{P S} y_{r e l}-f_{N S\left(x_{N S}\right)} \\
& +k_{P S} y_{r e l}=-m_{D} x_{G}(t)
\end{aligned}
$$

where $x_{N S}$ is the NS stroke (relative displacement between the terminals of the NS element-NS mechanism), as presented in Figures 2-3:

$x_{N S}=x_{r e l}-y_{r e l}$

and $f_{N S(x N S)}$ is the total elastic force that is generated by the NS mechanism.

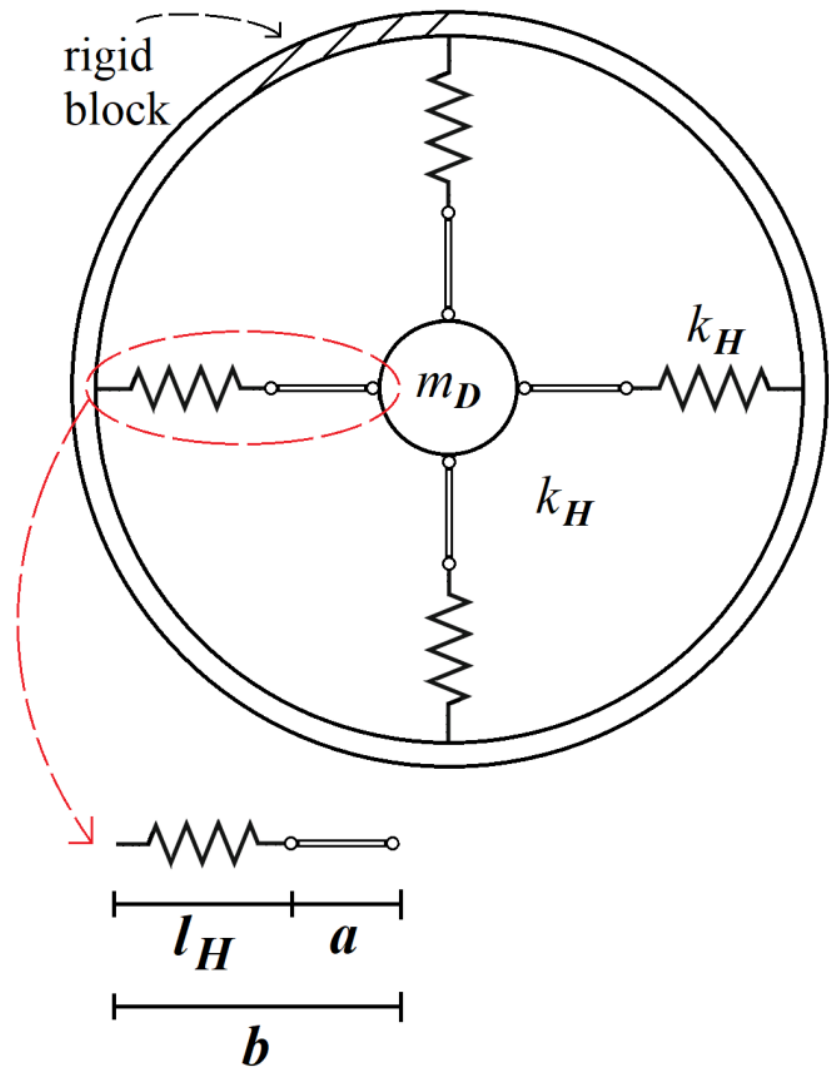

Figure 4. Plan view of the proposed NS configuration with precompressed spiral springs positioned radially (4 in this Figure) with respect to the additional mass's vertical axis

In order to calculate the exact value of the generated NS, first the potential energy due to the deformation of the conventional spiral pre-stressed spiral linear springs $k_{H}$ is calculated as:

$U_{N S}\left(x_{N S}\right)=N_{k_{H}} \frac{1}{2} k_{H}\left(l_{H}-l_{H I}\right)^{2}$

where $l_{H I}$ is the length of the undeformed springs $k_{H}$, and $l_{H}$ is the length of $k_{H}$ in the deformed state at any given moment (Figure 3). $N_{k H}$ is the number of the pre-stressed spiral springs that are positioned radially with respect to the additional mass's $\left(m_{D}\right)$ vertical axis. Based on the configuration presented in Figures 2-4, the $l_{H}$ is:

$l_{H}=b-\left(a^{2}-x_{N S}^{2}\right)^{1 / 2}$ 
where $x_{N S}$ is the NS stroke (Equation 3). Consequently, the elastic geometric nonlinear NS force that corresponds to the negative stiffness is:

$$
\begin{aligned}
& f_{N S}\left(x_{N S}\right)=\frac{\partial U_{N S}}{\partial x_{N S}}=-N_{k_{H}} k_{H}\left(1+\frac{l_{H I}-b}{\sqrt{a^{2}-x_{N S}^{2}}}\right) x_{N S}= \\
& -N_{k_{H}} k_{H}\left[1+c_{I} \frac{1}{\left(1-x_{N S}^{2} / a^{2}\right)^{1 / 2}}\right] x_{N S} \\
& c_{I}=\frac{l_{H I}-b}{a}, \quad-1 \leq c_{I} \leq 0
\end{aligned}
$$

Having a closed form for the generated elastic NS force, the negative stiffness produced by the elastic springs $k_{H}$ in the presented NS mechanism is:

$$
\begin{aligned}
& k_{N S}=\frac{\partial f_{N S}}{\partial x_{N S}}=-N_{k_{H}} k_{H}\left\lfloor 1+\frac{l_{H I}-b}{a\left(1-x_{N S}^{2} / a^{2}\right)^{3 / 2}}\right\rfloor= \\
& -N_{k_{H}} k_{H}\left[1+c_{I} \frac{1}{\left(1-x_{N S}^{2} / a^{2}\right)^{3 / 2}}\right]
\end{aligned}
$$

where $a$ and $b$ are the geometrical parameters presented in Figure 4. In order to exploit the advantages that the inherent nonlinear nature of NS offers, such as robustness, broadband response and energy sinks, the parameters of the NS mechanism are selected so that the range of the generated NS (maximum - minimum value) is large. The maximum (absolute) value of the generated NS is obtained in the static equilibrium position, as indicated by Equation (8), where the NS stroke is equal to zero:

$x_{N S, \text { min }}=0 \Rightarrow$

$k_{N S, x_{N S}=0}=-N_{k_{H}} k_{H}\left[1+c_{I}\right] \quad(\max$ abs value $)$

The minimum (absolute) value can be calculated, respectively, when the NS stroke attains its maximum value (absolute). Assuming that this value is 0.9 of $a$, the $k_{N S, \min }$ is:

$$
\begin{aligned}
& x_{N S, \text { max }}=0.9 a \Rightarrow \\
& k_{N S, x_{N S}=0.9 a}=-N_{k_{H}} k_{H}\left[1+12.075 c_{I}\right] \quad(\min \text { abs value })
\end{aligned}
$$

Thus, the maximum range of the generated NS can be set as a design variable. This fact enables the evaluation of the effectiveness of the KDamper-based designs with respect to the geometric nonlinearity. Since $c_{I}$ is negative, as the NS stroke increases, the generated NS decreases in absolute value. The generated NS in the system's fully deformed state (maximum NS stroke) can be expressed as a percentage of the initial (maximum absolute) NS (that is when the system is in equilibrium), and is expressed as:
$k_{N S, x_{N S}=0.9 a}=P_{N S} k_{N S, x_{N S}=0} \Rightarrow$

$P_{N S}=\frac{k_{N S, x_{N S}=0.9 a}}{k_{N S, x_{N S}=0}}$

Thus, the geometric parameter $c_{I}$ is obtained, given the desired reduction percentage $\left(1-P_{N S}\right)$ of the generated NS of the proposed mechanism:

$$
\begin{aligned}
& \frac{k_{N S, x_{N S}=0.9 a}}{k_{N S, x_{N S}=0}}=\frac{-N_{k_{H}} k_{H}\left[1+12.075 c_{I}\right]}{-N_{k_{H}} k_{H}\left[1+c_{I}\right]}=P_{N S} \quad \Rightarrow \\
& c_{I}=-\frac{1-P_{N S}}{12.075-P_{N S}}=\frac{-\left(1-P_{N S}\right)}{11.075+\left(1-P_{N S}\right)}
\end{aligned}
$$

In Table 1 and Figure 5, the dimensionless parameter $c_{I}$ and the generated NS are presented respectively, for various values of the $P_{N S \text {. }}$

Table 1. Dimensionless parameter $c_{I}$ for various $P_{N S}$ values

\begin{tabular}{|c|c|c|c|c|c|c|}
\hline$\left(1-P_{N S}\right)(\%)$ & 0 & 10 & 20 & 30 & 40 & 50 \\
\hline$c_{I}$ & 0.000 & -0.009 & -0.018 & -0.026 & -0.035 & -0.043 \\
\hline
\end{tabular}

It is observed that the generated NS is significantly reduced near the fully deformed state of the NS mechanism. That is the reason why the mean value of the generated NS is not in direct relation with the variation of the generated NS $\left(P_{N S}\right)$.

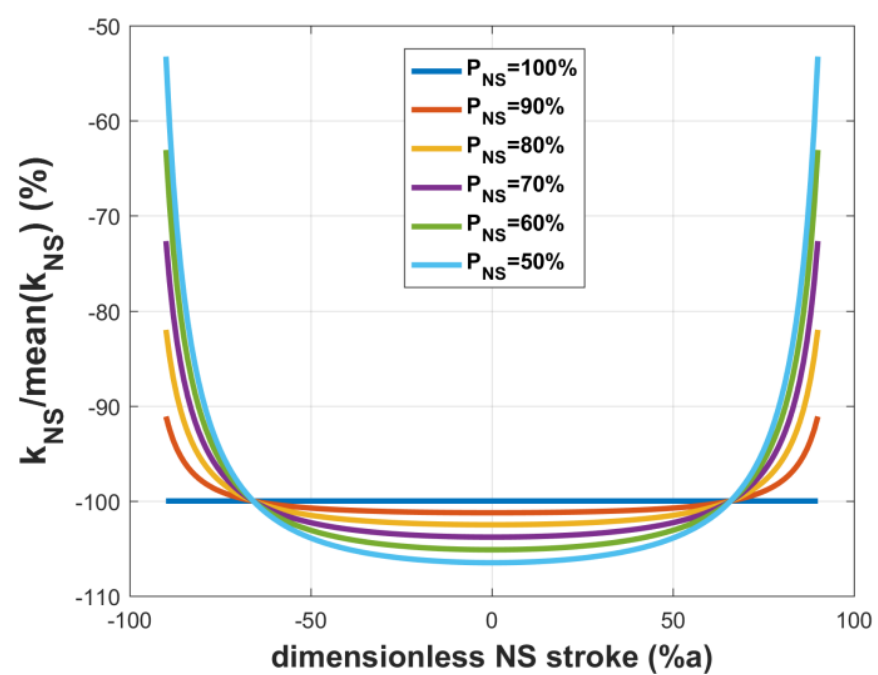

Figure 5. Generated NS of the proposed NS mechanism designed so the mean NS is equal for all the values of the design variable $P_{N S}$

In Figure 6, the elastic NS force $f_{N S}$ is presented, and it is observed that the total generated elastic force $f_{N S}$ presents significant alterations only in the extreme values of the NS stroke, which is to be expected as in these regions is where the NS is significantly reduced (in absolute value). 


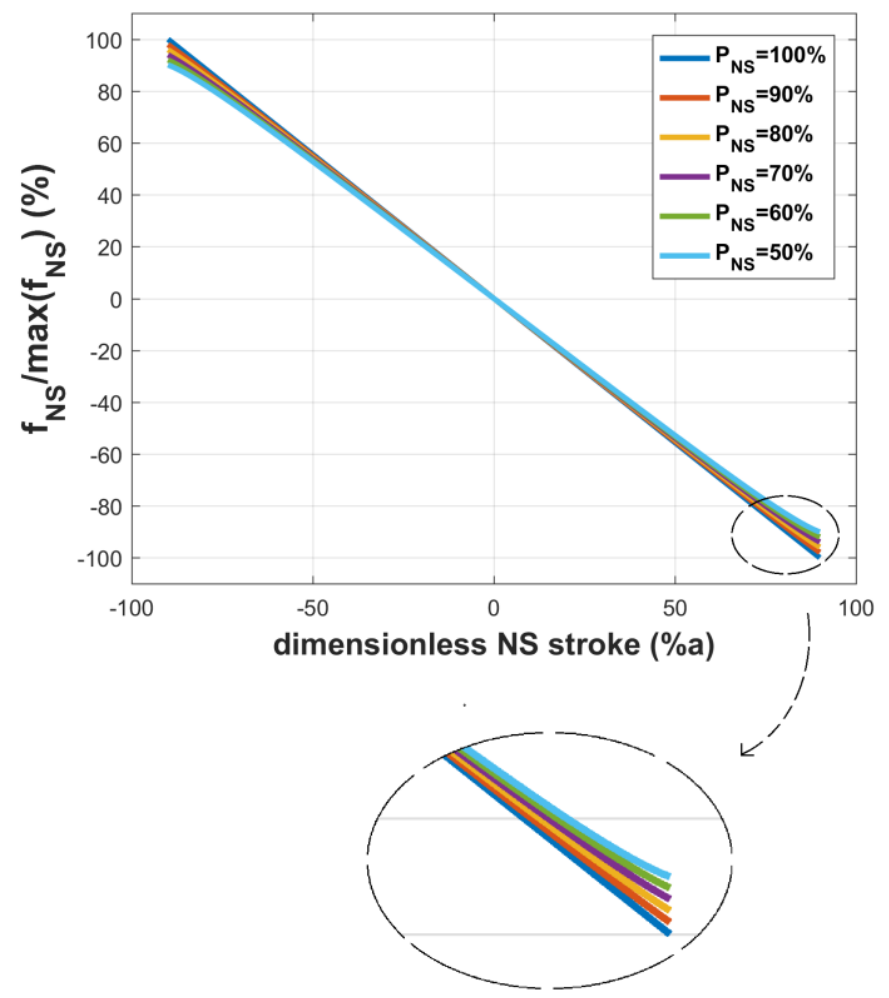

Figure 6. Generated NS of the proposed NS mechanism for various values of the design variable $P_{N S}$

\section{OPTIMAL DESIGN OF NONLINEAR NEGATIVE STIFFNESS ABSORBERS}

In the static equilibrium position, the system is designed to have a (static) nominal frequency equal to:

$$
f_{0}=\frac{1}{2 \pi} \sqrt{\frac{m_{\text {total }}}{k_{0}}}=\frac{1}{2 \pi} \sqrt{\frac{\left(m+m_{D}\right)}{k_{R}+\frac{k_{P S} k_{N S, x_{N S}=0}}{k_{P S}+k_{N S, x_{N S}=0}}}}
$$

In order for the system to remain stable in its operating range, accounting all possible variations in the stiffness values of the positive and negative stiffness elements stiffnesses is necessary. Instability arises when the nominal system frequency (static or dynamic) tends to infinite (or respectively the nominal stiffness $k_{0}$ tends to zero). Therefore, with respect to the value of the NS element, the static equilibrium position where NS obtains its maximum (absolute) value, is the critical one. In addition, all elements in practice (springs, dampers, masses) present manufacturing faults. Thus, it should be ensured that in the static equilibrium position while also accounting for simultaneous manufacturing faults $( \pm \varepsilon)$ in all stiffness elements, the system remains stable:

$$
\bar{k}_{0}=\bar{k}_{R}+\frac{\bar{k}_{P S} \bar{k}_{N S, x_{N S}=0}}{\bar{k}_{P S}+\bar{k}_{N S, x_{N S}=0}} \geq 0
$$

where $\bar{k}_{R}, \bar{k}_{P S}, \bar{k}_{N S, x_{N S}=0}$ are the stiffnesses accounting manufacturing faults. The worst combination in the variation of the stiffness elements is when the positive stiffness elements $k_{R}$ and $k_{P S}$ values decrease, and the NS element value increases its absolute value. According to Equation (8) the generated NS of the configuration presented in Figures 2-4 increases its absolute value when the value of $k_{H}$ elements increases. Thus, the stiffness values of all the elements can be expressed with respect to their design parameters as:

$$
\begin{aligned}
& \bar{k}_{R}=\left(1-\varepsilon_{R}\right) k_{R} \\
& \bar{k}_{P S}=\left(1-\varepsilon_{P S}\right) k_{P S} \\
& \bar{k}_{N S, x_{N S}=0}=-N_{k_{H}}\left(1+\varepsilon_{N S}\right) k_{H}\left[1+c_{I}\right]
\end{aligned}
$$

Therefore, assuming that the nominal static frequency of the EKD and the initial maximum (absolute) value of the NS element are known, the rest of the stiffness element result by solving the system of Equations (13-14). The manufacturing faults of the stiffness elements are design variables of the EKD and hereby expressed as stability factors $\varepsilon_{R}, \varepsilon_{P S}$, and $\varepsilon_{N S}$.

Once the equations of motion of the controlled system with the EKD are stated (Equations 2) and the relations between the stiffness elements are determined (Equations 13-15), the goal now is to select the optimal system parameters in order for the dynamic responses of the controlled system to be the best possible. There are numerous design approaches for the selection of a vibration absorber parameters. In this paper, the design is based on an optimization procedure which accounts for geometrical constraints and constructional limitations, in order for the design to be as realistic as possible, and at the same time effective. For the optimization process, harmony search algorithm (HS), a novel metaheuristic algorithm, is adopted, further information of which can be found in [62].

The objective function, the constraints, the values of the independent variables and the steps of the design procedure are described below:

1. Select the structural system's properties (mass $m$, load type) to be controlled;

2. Assign values to the (constant) parameters: additional mass $m_{D}$ and stability factors $\varepsilon_{R}, \varepsilon_{P S}$, and $\varepsilon_{N S}$ based on previous work of KDamper-based concepts;

$m_{D}=0.1 \% m$

$\varepsilon_{R}=5 \%$

$\varepsilon_{P S}=5 \%$

$\varepsilon_{N S}=5 \%$

3. Set the objective function (OF) as the minimization of the structural relative to the ground displacement;

$\min : \max \left|x_{r e l}\right| \quad(O F)$ 
4. Select a value for the $P_{N S}$ design variable;

5. Select an upper (absolute) limit to the mean generated NS element's value, and the maximum NS stroke. A starting set of values can be obtained from previous work:

$\operatorname{mean}\left|k_{N S}\right| \leq 100 \mathrm{kN} / \mathrm{m} / \mathrm{tn}$

$\max \left|x_{N S}\right| \leq 0.10 m$

6. The length of the rod, a, in the proposed articulated mechanism presented in Figures 2-4 is calculated based on the assumption of the previous section and step 5:

$a=\max \left|x_{N S}\right| / 0.9=0.111 m$

7. Select an upper bound to the values of the artificial dampers $c_{N S}, c_{P S}$ with respect to the superstructure mass $\mathrm{m}$. In this case as well, a starting set of values can be obtained from previous work:

$c_{P S} \leq 20 \mathrm{kNs} / \mathrm{m} / \mathrm{tn}$

$c_{N S} \leq 20 \mathrm{kNs} / \mathrm{m} / \mathrm{tn}$

8. The nominal (static) frequency of the EKD system varies in the range:

$f_{0} \in\left[\begin{array}{ll}0.1 & 2\end{array}\right](H z)$

The design of the proposed EKD is presented schematically in the flowchart of Figure 7. The convergence criteria mentioned in the flowchart below are:

1. An acceleration filter (AF) is imposed in all the different set of optimized EKDs (with different $P_{N S}$ ) in order to have an equal comparison basis, that is each set of EKD will have equal maximum structural acceleration, and thus the comparison will mainly be based on the structural relative displacement and negative stiffness stroke $x_{N S}$;

$\max |\ddot{x}| \leq A F$

2. The resulting negative stiffness stroke $x_{N S}$ is assumed to be less than $90 \%$ of the length of the articulated mechanism $a$ (initial guess). The initial value of the rod length $a$ is selected based on previous work of EKD (step 6 of optimization) for similar stiffness, mass, and damping values. If it exceeds the initial value of $0.9 a$, a larger value for a will be selected;

$\max \left|x_{N S}\right| \leq 90 \% a$

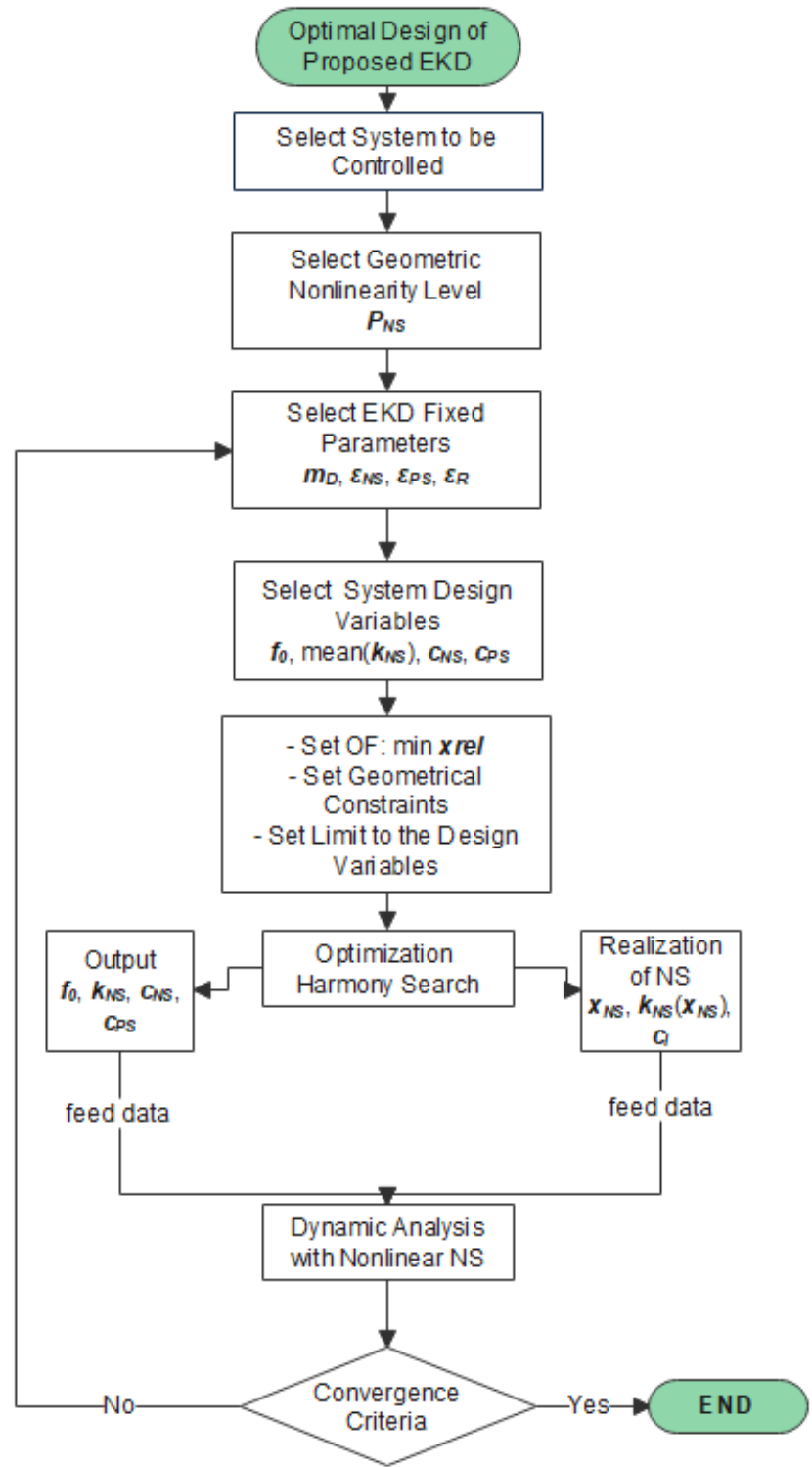

Figure 7. Flowchart of the proposed EKD design

The controlled structure is subjected to different dynamic loads, that are representative of the respective structural system to be examined. For example, a multi-story structure will be subjected to a seismic action, while a wind turbine tower to an aerodynamic load. For this reason, two different test load cases will be considered:

1. Ground motions. Real earthquakes are random events that vary from site to site, and even for the same location can present significant differences with respect to their magnitude, duration, frequency content, etc. For this reason, in this paper, an artificial accelerogram is generated using the SeismoArtif software [63], and is designed to match the EC8 acceleration response spectrum with characteristics: ground type $\mathrm{C}$, spectral acceleration $0.36 \mathrm{~g}$, spectrum type $\mathrm{I}$, and importance class II, and is presented in Figure 8. 


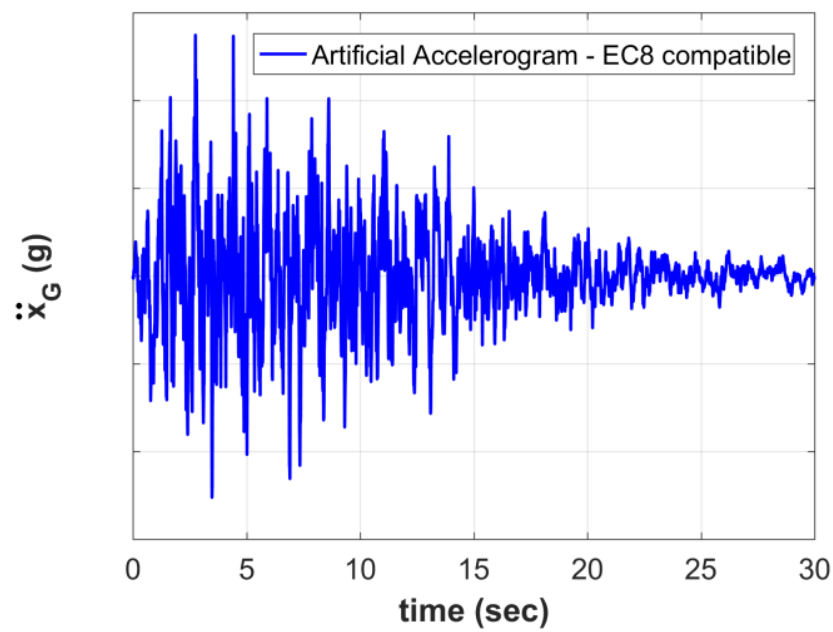

Figure 8. Load case I: artificial accelerogram compatible to the EC8 acceleration response spectrum

2. Aerodynamic load. Wind loads are difficult to model due to their random nature. For this reason, an impulsive load is considered as an extreme case of a wind gust.

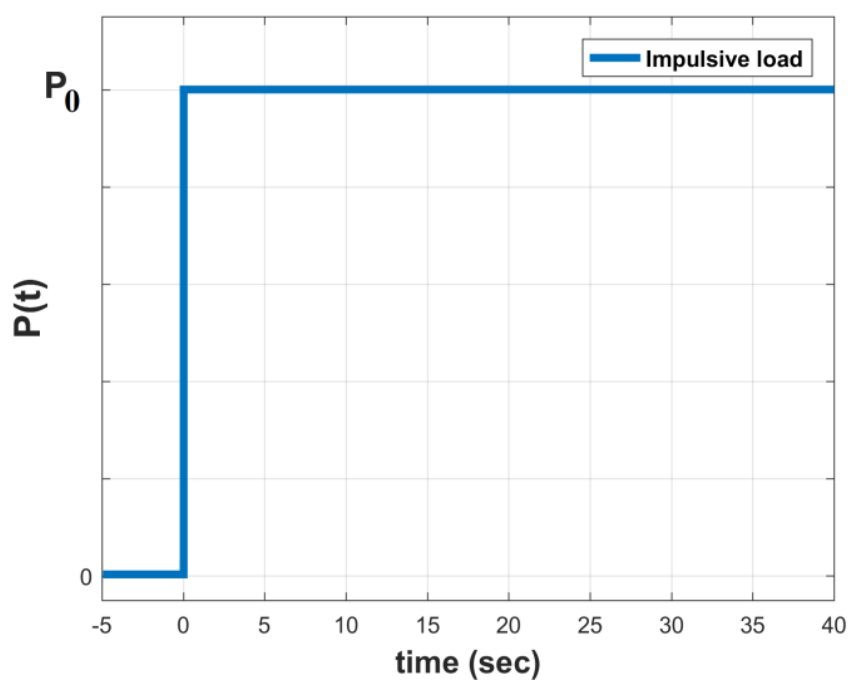

Figure 9. Load case II: impulsive constant load

\section{NUMERICAL RESULTS}

In both examined test cases, a structure mass of 300tn is selected as a reference value. Regarding the $P_{N S}$ design variable, three values are selected in order to observe the effect of the geometric nonlinearity level to the structural dynamic responses, and are: i) $P_{N S}=100 \%$ (linear behavior), ii) $P_{N S}=80 \%$ (moderate nonlinearity), and iii) $P_{N S}=50 \%$ (extreme nonlinearity).

\section{A. Load case I: Ground Motion (earthquake)}

In this section, an artificial accelerogram is generated to match the EC8 acceleration response spectrum, as described in section III of the paper, and is imposed on the controlled structure. The acceleration filter set as constraint is set equal to $70 \%$ of the artificial acceleration PGA (Peak Ground
Acceleration), in order to have an equal comparison basis between the results for different $P_{N S \text {. }}$

In Figure 10, the generated negative stiffness is presented for all the different values of $P_{N S}$ design variable $(100 \%, 80 \%$, $50 \%)$. It is observed that by decreasing the value of $P_{N S}$, the generated NS presents significant variations, $0 \%, 20 \%$, and $50 \%$, respectively, that are directly related to the resulting NS stroke, $x_{N S}$, which is presented below in Figure 11.

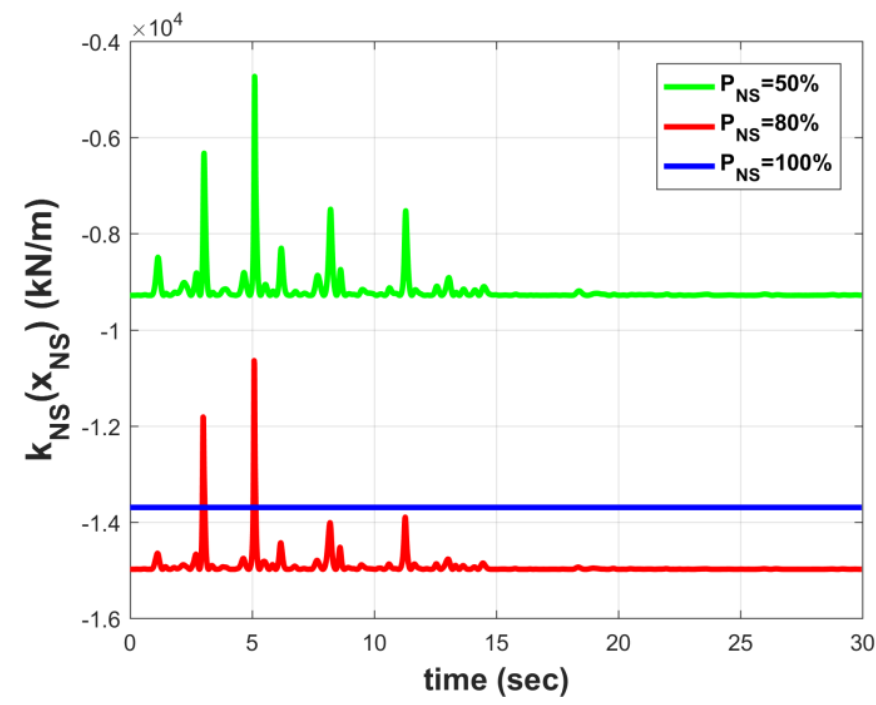

Figure 10. Generated NS ( $\left.k_{N S}\right)$ for all the examined values of $P_{N S}$ (ground motion load case)

The NS stroke, $x_{N S}$, as well as the relative to the ground structural displacement $x_{\text {rel }}$, which is presented in Figure 12, do not present significant differences, with respect to their maximum (absolute) values. That is because the dynamic responses of the controlled structure with the EKD (relative displacements, $\left.x_{N S}, x_{r e l}\right)$ present specific peaks, that relate to the same specific peaks of the artificial accelerogram imposed on the structure.

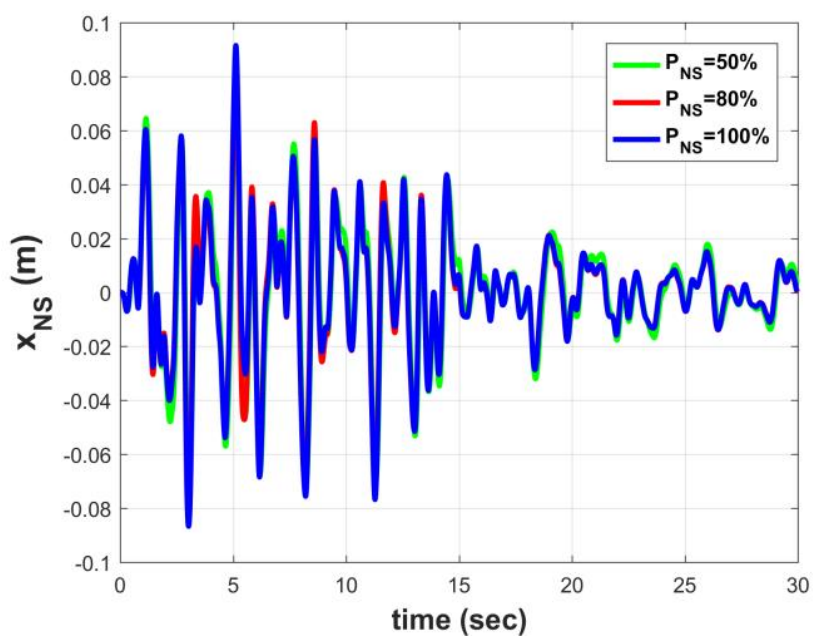

Figure 11. Resulting NS stroke $\left(x_{N S}\right)$ for all the examined values of $P_{N S}$ (ground motion load case)

As a result, the generated NS is significantly altered momentarily, at the point at which the acceleration peaks are 
presented. This does not affect the structural behavior as the geometric nonlinearity only appear in these moments. As a result, it is safe to assume that this kind of geometric nonlinearity is ineffective in vibration absorption of structures imposed on seismic actions.

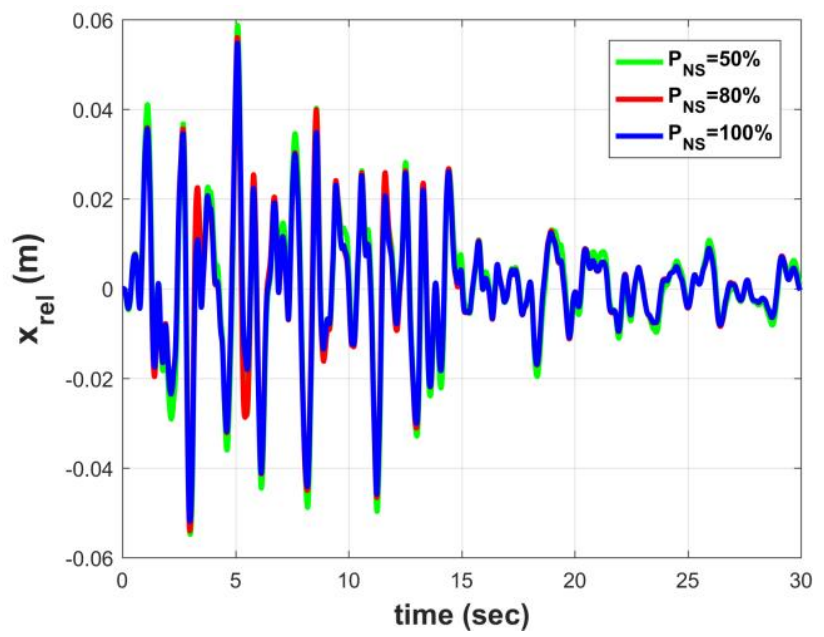

Figure 12. Resulting structural relative to the ground displacement $\left(x_{r e l}\right)$ for all the examined values of $P_{N S}$ (ground motion load case)

\section{B. Load case II: Impulsive Load (wind gust)}

In this section, an impulsive load with constant value is considered in order to model the random nature of gust winds in structures. The amplitude of the dynamic load is set equal to $1500 \mathrm{kN}$ and is the same for all the examined cases (with different $P_{N S}$ ). In addition, the nominal (static) frequency of all systems is assumed to be the same, in order to have an equal comparison basis. That is because the static nominal frequency determines the resulting maximum absolute acceleration of the controlled structure, as the maximum value is presented in the beginning of the vibration.

In Figure 13, the generated negative stiffness is presented for all the values of $P_{N S}$. It is observed that by decreasing the $P_{N S}$, indeed the generated NS presents significant variations that are directly related to the resulting NS stroke (Figure 14).

The NS stroke varies in the first cycles of vibration, and then is 'stabilized' in a certain value, which is to be expected when we considered a dynamic load of impulsive nature with constant value. This fact explains the reason why the 'stabilized' generated NS is different, and more specifically lower (in absolute value), as compared to the value in the equilibrium position of the controlled system.

As a consequence, as the $P_{N S}$ decreases, or respectively as the geometric nonlinearity level increases, the system frequency after some cycles of vibration, alters, as presented in Figure 15 where the structural relative displacement is presented. It is observed that while the maximum value of the displacement is practically the same, the final displacements are lower as the geometric nonlinearity level increases $\left(P_{N S}\right.$ decreases). That is because, as $P_{N S}$ decreases, the resulting value of the generated NS is decreased in absolute value. As s consequence, the equivalent stiffness of the system increases, reducing the displacements, highlighting the beneficial role of extreme nonlinearity in dynamic loads of impulsive type. More specifically, the structural $\left(x_{r e l}, x_{N S}\right)$ dynamic responses obtain their maximum (absolute) values in the most part of the vibration time, and for this reason the generated NS significantly alters in the most part of the vibration.

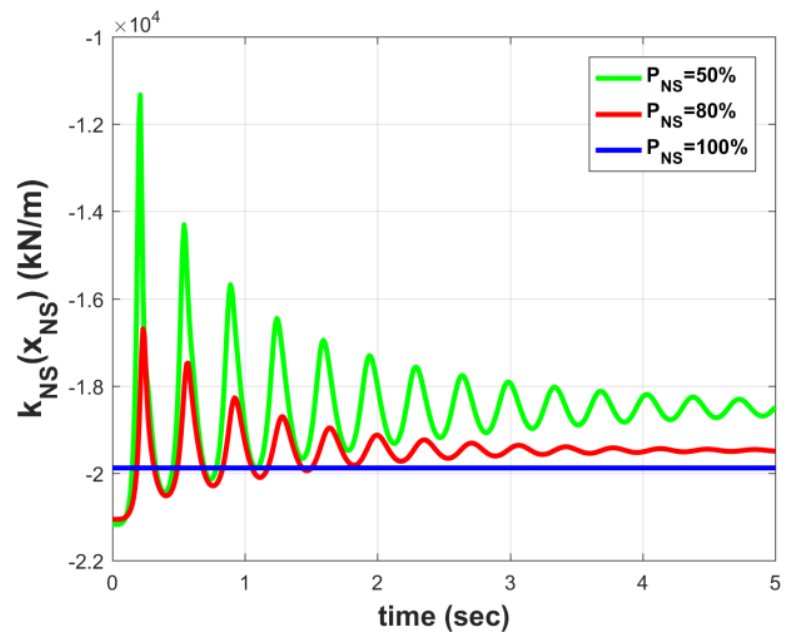

Figure 13. Generated NS ( $\left.k_{N S}\right)$ for all the examined values of $P_{N S}$ (impulsive load case)

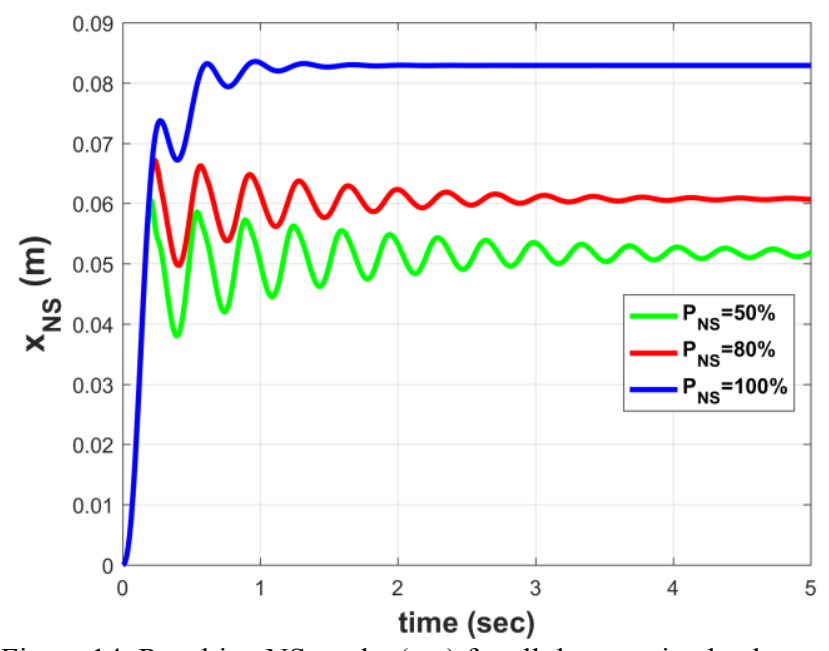

Figure 14. Resulting NS stroke $\left(x_{N S}\right)$ for all the examined values of $P_{N S}$ (impulsive load case) 


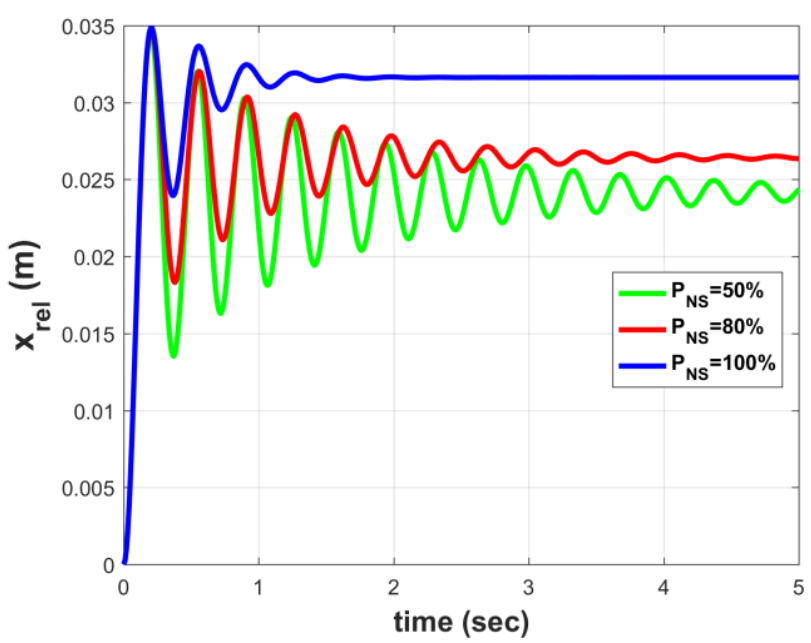

Figure 15. Resulting structural relative to the ground displacement $\left(x_{r e l}\right)$ for all the examined values of $P_{N S}$ (impulsive load case)

\section{CONCLUSION}

In this paper, the EKD is employed in a SDoF structure, realizing the negative stiffness element with a displacementdependent configuration that generates controlled NS. In addition, the proposed design allows the implementation of multiple conventional spiral springs. This way the safety of the NS mechanism (avoidance of buckling and exceedance of torsional strength) is ensured. The generated NS varies from 'linear' to extreme (geometric) nonlinear, in order to determine the beneficial role of geometric nonlinearity, with respect to the examined structural system.

For this reason, two different load cases are examined, i.e., a ground motion, and an impulsive load of constant value. The first load case is representative to systems subjected to earthquakes, while the second to wind gusts, that have an impulsive nature. Based on the numerical results obtained, the geometric nonlinearity is beneficial to the second case only, where the structural dynamic responses (both the structure relative displacement and the NS stroke) present significant variations during the oscillation. That is because the generated NS value presents its maximum variation, where the NS stoke is larger according to Figure 5. Thus, in earthquake motions where there are only a few strong pulses, the generated NS value is significantly altered in a small portion of the vibration (Figures 11-12). On the contrary, in the case of aerodynamic loads, the dynamic responses obtain their maximum (absolute) values in the most part of the vibration (Figures 14-15), and for this reason the generated NS significantly alters in the most part of the vibration.

Finally, in future work, the EKD can be designed to include nonlinear positive stiffness elements as well as nonlinear viscous dampers, as this work in limited in introducing nonlinearity (extreme) only in the negative stiffness element.

\section{ACKNOWLEDGMENT}

This work has been supported by the Bodossaki Foundation - Scholarship for Postdoctoral studies.

\section{References}

[1] H. Frahm, "Device for damping of bodies," US patent \#989958, 1911.

[2] J. P. Den Hartog, Mechanical Vibrations, 4th ed. New York, 1956.

[3] R. W. Luft, "Optimal Tuned Mass Dampers for Buildings," J. Struct. Div., vol. 105, no. 12, pp. 27662772, 1979.

[4] R. J. McNamara, "Tuned Mass Dampers for Buildings," J. Struct. Div., vol. 103, no. 9, pp. 17851798, 1977.

[5] L. Qin, W. Yan, and Y. Li, "Design of frictional pendulum TMD and its wind control effectiveness," $J$. Earthq. Eng. Eng. Vib., vol. 29, no. 5, pp. 153-157, 2009.

[6] M. Ramezani, A. Bathaei, and A. K. Ghorbani-Tanha, "Application of artificial neural networks in optimal tuning of tuned mass dampers implemented in highrise buildings subjected to wind load," Earthq. Eng. Eng. Vib., vol. 17, no. 4, pp. 903-915, Oct. 2018.

[7] T. Haskett, B. Breukelman, J. Robinson, and J. Kottelenberg, "Tuned mass dampers under excessive structural excitation," Rep. Motioneering Inc, 2004.

[8] N. Debnath, S. K. Deb, and A. Dutta, "Multi-modal vibration control of truss bridges with tuned mass dampers under general loading," JVC/Journal Vib. Control, vol. 22, no. 20, pp. 4121-4140, Dec. 2016.

[9] J.-L. Chen and C. T. Georgakis, "Spherical tuned liquid damper for vibration control in wind turbines," J. Vib. Control, vol. 21, no. 10, pp. 1875-1885, Jul. 2015.

[10] J. Mayet and H. Ulbrich, "First-order optimal linear and nonlinear detuning of centrifugal pendulum vibration absorbers," J. Sound Vib., vol. 335, pp. 3454, Jan. 2015.

[11] L. L. Chung, L. Y. Wu, H. H. Huang, C. H. Chang, and K. H. Lien, "Optimal design theories of tuned mass dampers with nonlinear viscous damping," Earthq. Eng. Eng. Vib., vol. 8, no. 4, pp. 547-560, Dec. 2009.

[12] B. Han and C. Li, "Seismic response of controlled structures with active multiple tuned mass dampers," Earthq. Eng. Eng. Vib., vol. 5, no. 2, pp. 205-213, Dec. 2006.

[13] M. H. Rafieipour, A. K. Ghorbani-Tanha, M. Rahimian, and R. Mohammadi-Ghazi, "A novel semiactive TMD with folding variable stiffness spring," Earthq. Eng. Eng. Vib., vol. 13, no. 3, pp. 509-518, Sep. 2014.
Z. Wang, Z. Chen, and J. Wang, "Feasibility study of a large-scale tuned mass damper with eddy current 
damping mechanism," J. Earthq. Eng. Eng. Vib., vol. 11, no. 3, pp. 391-401, Sep. 2012.

[15] R. Yang, X. Zhou, and X. Liu, "Seismic structural control using semi-active tuned mass dampers," Earthq. Eng. Eng. Vib., vol. 1, no. 1, pp. 111-118, 2002.

[16] S. Ankireddi and H. T. Y. Yang, "Simple ATMD control methodology for tall buildings subject to wind loads," J. Struct. Eng., vol. 122, no. 1, pp. 83-91, Jan. 1996.

[17] F. Ricciardelli, A. D. Pizzimenti, and M. Mattei, "Passive and active mass damper control of the response of tall buildings to wind gustiness," Eng. Struct., vol. 25, no. 9, pp. 1199-1209, 2003.

[18] W. Molyneaux, Supports for Vibration Isolation. G. Britain: ARC/CP-322, Aer Res Council, 1957.

[19] D. L. Platus and D. L.Platus, "Negative-stiffnessmechanism vibration isolation systems," in Proc. of SPIE, 1992, vol. 1619, no. Feb, pp. 44-54.

[20] A. Carrella, M. J. Brennan, and T. P. Waters, "Static analysis of a passive vibration isolator with quasi-zerostiffness characteristic," J. Sound Vib., vol. 301, no. 35, pp. 678-689, 2007.

[21] J. Winterflood, D. . Blair, and B. Slagmolen, "High performance vibration isolation using springs in Euler column buckling mode," Phys. Lett. A, vol. 300, no. 2-3, pp. 122-130, Jul. 2002.

[22] L. N. Virgin, S. T. Santillan, and R. H. Plaut, "Vibration isolation using extreme geometric nonlinearity," J. Sound Vib., vol. 315, no. 3, pp. 721731, Aug. 2008.

[23] A. V. Dyskin and E. Pasternak, "Mechanical effect of rotating non-spherical particles on failure in compression," in Philosophical Magazine, 2012, vol. 92, no. 28-30, pp. 3451-3473.

[24] W. S. Robertson, M. R. F. Kidner, B. S. Cazzolato, and A. C. Zander, "Theoretical design parameters for a quasi-zero stiffness magnetic spring for vibration isolation," J. Sound Vib., vol. 326, no. 1-2, pp. 88103, Sep. 2009.

[25] N. Zhou and K. Liu, "A tunable high-static-lowdynamic stiffness vibration isolator," J. Sound Vib., vol. 329, no. 9, pp. 1254-1273, Apr. 2010.

[26] N. Attary, M. Symans, and S. Nagarajaiah, "Development of a rotation-based negative stiffness device for seismic protection of structures," J. Vib. Control, vol. 23, no. 5, pp. 853-867, Mar. 2017.

[27] R. DeSalvo, "Passive, nonlinear, mechanical structures for seismic attenuation," J. Comput. Nonlinear Dyn., vol. 2, no. 4, pp. 290-298, Oct. 2007.

[28] H. Iemura and M. H. Pradono, "Advances in the development of pseudo-negative-stiffness dampers for seismic response control," Struct. Control Heal. Monit., vol. 16, no. 7-8, p. n/a-n/a, Nov. 2009.

[29] A. A. Sarlis, D. T. R. Pasala, M. C. Constantinou, A. M. Reinhorn, S. Nagarajaiah, and D. P. Taylor, "Negative Stiffness Device for Seismic Protection of Structures," in Journal of Structural Engineering, vol. 139, no. 7, Corfu,Greece, 2012, pp. 1124-1133.

[30] T. D. Le and K. K. Ahn, "A vibration isolation system in low frequency excitation region using negative stiffness structure for vehicle seat," J. Sound Vib., vol. 330, no. 26, pp. 6311-6335, Dec. 2011.

[31] C. M. Lee, V. N. Goverdovskiy, and A. I. Temnikov, "Design of springs with 'negative' stiffness to improve vehicle driver vibration isolation," J. Sound Vib., vol. 302, no. 4-5, pp. 865-874, May 2007.

[32] C. M. Lee and V. N. Goverdovskiy, "A multi-stage high-speed railroad vibration isolation system with 'negative' stiffness," J. Sound Vib., vol. 331, no. 4, pp. 914-921, Feb. 2012.

[33] J. Zhou, D. Xu, and S. Bishop, "A torsion quasi-zero stiffness vibration isolator," J. Sound Vib., vol. 338, pp. 121-133, Mar. 2015.

[34] E. Baravelli and M. Ruzzene, "Internally resonating lattices for bandgap generation and low-frequency vibration control," J. Sound Vib., vol. 332, no. 25, pp. 6562-6579, Dec. 2013.

D. M. Correa, T. Klatt, S. Cortes, M. Haberman, D. Kovar, and C. Seepersad, "Negative stiffness honeycombs for recoverable shock isolation," Rapid Prototyp. J., vol. 21, no. 2, pp. 193-200, Mar. 2015.

[36] P. Michelis and V. Spitas, "Numerical and experimental analysis of a triangular auxetic core made of CFR-PEEK using the Directionally Reinforced Integrated Single-yarn (DIRIS) architecture," Compos. Sci. Technol., vol. 70, no. 7, pp. 1064-1071, Jul. 2010.

[37] K. Virk et al., "SILICOMB PEEK Kirigami cellular structures: mechanical response and energy dissipation through zero and negative stiffness," Smart Mater. Struct., vol. 22, no. 8, p. 084014, Jul. 2013.

[38] R. Lakes, P. Rosakis, and A. Ruina, "Microbuckling instability in elastomeric cellular solids," J. Mater. Sci., vol. 28, no. 17, pp. 4667-4672, Jan. 1993.

D. A. Saravanos, D. I. Chortis, D. S. Varelis, and P. Fellow, "Linearized Frequencies and Damping in Composite Laminated Beams Subject to Buckling," Artic. J. Vib. Acoust., 2013.

[40] V. Spitas, C. Spitas, and P. Michelis, "Modeling of the elastic damping response of a carbon nanotubepolymer nanocomposite in the stress-strain domain using an elastic energy release approach based on 
stick-slip," Mech. Adv. Mater. Struct., vol. 20, no. 10, pp. 791-800, Nov. 2013.

[41] R. S. Lakes, "Extreme damping in composite materials with a negative stiffness phase," Phys. Rev. Lett., vol. 86, no. 13, pp. 2897-2900, Mar. 2001.

[42] T. Jaglinski, D. Kochmann, D. Stone, and R. S. Lakes, "Composite materials with viscoelastic stiffness greater than diamond," Science (80-. )., vol. 315, no. 5812, pp. 620-622, Feb. 2007.

[43] L. Dong and R. Lakes, "Advanced damper with high stiffness and high hysteresis damping based on negative structural stiffness," Int. J. Solids Struct., vol. 50, no. 14-15, pp. 2416-2423, Jul. 2013.

[44] C. S. Wojnar and D. M. Kochmann, "A negativestiffness phase in elastic composites can produce stable extreme effective dynamic but not static stiffness," Philos. Mag., vol. 94, no. 6, pp. 532-555, Feb. 2014.

[45] I. Antoniadis, D. Chronopoulos, V. Spitas, and D. Koulocheris, "Hyper-damping properties of a stiff and stable linear oscillator with a negative stiffness element," J. Sound Vib., 2015.

[46] D. Chronopoulos, I. Antoniadis, M. Collet, and M. Ichchou, "Enhancement of wave damping within metamaterials having embedded negative stiffness inclusions," Wave Motion, vol. 58, pp. 165-179, Nov. 2015.

[47] M. Wang, F. Sun, and S. Nagarajaiah, "Simplified optimal design of MDOF structures with negative stiffness amplifying dampers based on effective damping,” Struct. Des. Tall Spec. Build., Aug. 2019.

[48] M. Wang, F. fei Sun, and H. jian Jin, "Performance evaluation of existing isolated buildings with supplemental passive pseudo-negative stiffness devices," Eng. Struct., 2018.

[49] I. A. Antoniadis, S. A. Kanarachos, K. Gryllias, and I. E. Sapountzakis, "KDamping: A stiffness based vibration absorption concept," JVC/Journal Vib. Control, vol. 24, no. 3, pp. 588-606, 2018.

[50] K. A. Kapasakalis, I. A. Antoniadis, and E. J. Sapountzakis, "Performance assessment of the KDamper as a seismic Absorption Base," Struct. Control Heal. Monit., vol. 27, no. 4, 2020.

[51] K. A. Kapasakalis, I. A. Antoniadis, and E. J. Sapountzakis, "Constrained optimal design of seismic base absorbers based on an extended KDamper concept," Eng. Struct., vol. 226, 2021.

[52] K. A. Kapasakalis, I. A. Antoniadis, and E. J. Sapountzakis, "Feasibility Assessment of Stiff Seismic Base Absorbers," J. Vib. Eng. Technol. 2021, pp. 117, Aug. 2021.

[53] K. A. Kapasakalis, I. A. Antoniadis, and E. J.
Sapountzakis, "A Soil-Dependent Approach for the Design of Novel Negative Stiffness Seismic Protection Devices," Appl. Sci. 2021, Vol. 11, Page 6295, vol. 11, no. 14, p. 6295, Jul. 2021.

[54] K. Kapasakalis, I. Antoniadis, and E. Sapountzakis, "Implementation of the KDamper as a Stiff Seismic Absorption Base: A Preliminary Assessment," Vib. Acoust. Res. J., vol. 1, no. 1, 2019.

[55] K. A. Kapasakalis, I. A. Antoniadis, and E. J. Sapountzakis, "STIFF vertical seismic absorbers," JVC/Journal Vib. Control, vol. 0, no. 0, pp. 1-13, Mar. 2021.

[56] M. Kalogerakou, K. Kapasakalis, I. Antoniadis, and E. Sapountzakis, "STIFF DYNAMIC ABSORBERS FOR THE VERTICAL SEISMIC PROTECTION OF STRUCTURES," 8th Int. Conf. Comput. Methods Struct. Dyn. Earthq. Eng. Methods Struct. Dyn. Earthq. Eng., pp. 2543-2556, 2021.

[57] M. E. Kalogerakou, K. A. Kapasakalis, I. A. Antoniadis, and E. J. Sapountzakis, "Vertical seismic protection of structures with inerter-based negative stiffness absorbers," Bull. Earthq. Eng., pp. 1-42, Jan. 2022.

[58] K. A. Kapasakalis, I. A. Antoniadis, E. J. Sapountzakis, and A. E. Kampitsis, "Vibration Mitigation of Wind Turbine Towers Using Negative Stiffness Absorbers," J. Civ. Eng. Constr., vol. 10, no. 3, pp. 123-139, Aug. 2021.

[59] K. Kapasakalis, I. Antoniadis, and E. Sapountzakis, "VIBRATION CONTROL OF WIND TURBINE TOWERS WITH KDAMPER-BASED DESIGNS," 8th Int. Conf. Comput. Methods Struct. Dyn. Earthq. Eng. Methods Struct. Dyn. Earthq. Eng., pp. 18121824, 2021.

[60] K. A. Kapasakalis, P. O. N. Bollano, E. J. Sapountzakis, and I. A. Antoniadis, "Comparison of alternative dynamic vibration mitigation approaches for wind turbine towers," in Proceedings of the International Conference on Structural Dynamic , EURODYN, 2020, vol. 1, pp. 1358-1372.

[61] A. Kampitsis, K. Kapasakalis, and L. Via-Estrem, "An integrated FEA-CFD simulation of offshore wind turbines with vibration control systems," Eng. Struct., vol. 254, p. 113859, Mar. 2022.

[62] Zong Woo Geem, Joong Hoon Kim, and G. V. Loganathan, "A New Heuristic Optimization Algorithm: Harmony Search," Simulation, vol. 76, no. 2, pp. 60-68, Feb. 2001.

[63] Seismosoft [2018], "SeismoArtif - A computer program for generating artificial earthquake accelerograms matched to a specific target response spectrum," 2018. [Online]. Available: http://www.seismosoft.com. 


\section{Contribution of Individual Authors to the Creation} of a Scientific Article (Ghostwriting Policy)

Dr. Konstantinos A. Kapasakalis was responsible for the conceptualization, methodology, software, formal analysis, data curation, writing, visualization and validation.

Dr. Evangelos J. Sapountzakis was responsible for the writing, review \& editing, methodology, resources and supervision.

Creative Commons Attribution License 4.0 (Attribution 4.0 International, CC BY 4.0)

This article is published under the terms of the Creative Commons Attribution License 4.0

https://creativecommons.org/licenses/by/4.0/deed.en_US 